\title{
Sports-related wrist and hand injuries: a review
}

\author{
Daniel M. Avery III, Craig M. Rodner and Cory M. Edgar
}

\begin{abstract}
Background: Hand and wrist injuries are common during athletics and can have a significant impact especially if initially disregarded. Due to their high level of physical demand, athletes represent a unique subset of the population.

Main body: The following is an overview of hand and wrist injuries commonly seen in athletics. Information regarding evaluation, diagnosis, conservative measures, and surgical treatment are provided.

Conclusion: Knowledge of these entities and special consideration for the athlete can help the team physician effectively treat these players and help them achieve their goals.

Keywords: Hand injuries, Wrist injuries, Sports, Return to play, Ligament, Fracture, Surgical treatment

Abbreviations: PA, Posteroanterior; CT, Computed tomography; MRI, Magnetic resonance imaging; SL, Scapholunate; DISI, Dorsal intercalated segmental instability; ECU, Extensor carpi ulnaris; TFCC, Triangular fibrocartilage complex; US, Ultrasound; FDP, Flexor digitorum profundus; UCL, Ulnar collateral ligament; MCPJ, Metacarpophalnageal joint; IP, Interphalangeal; ROM, Range of motion; AP, Anteroposterior; K-wires, Kirschner wires; PIP, Proximal interphalangeal; EDC, extensor digitorum communis; DIP, Distal interphalangeal; FDS, Flexor digitorum superficialis
\end{abstract}

\section{Background}

Approximately $25 \%$ of all sports-related injuries involve the hand or wrist $[1,2]$, and incidence is growing not only due to the competitive level of high school and collegiate athletes but also due to the activity level of the general population [3]. While the shoulder and knee are the commonly thought of in athletic injury, hand and wrist injuries are common and can have a significant impact especially if initially disregarded with a resultant delay to treatment.

Due to the high level of physical demand for function, athletes represent a unique subset of the population. Injury time can have a significant impact on scholarship opportunities or jeopardize professional aspirations with direct financial impact. Knowledge of common sports-related injuries and therapeutic strategies can help the physician effectively treat the athlete considering their sports, position, and timing during season. The following is an

\footnotetext{
* Correspondence: Danielavery04@yahoo.com University of Connecticut Musculoskeletal Institute, 263 Farmington Avenue, Farmington CT, 06030-4037, USA
}

(c) 2016 The Author(s). Open Access This article is distributed under the terms of the Creative Commons Attribution 4.0 International License (http://creativecommons.org/licenses/by/4.0/), which permits unrestricted use, distribution, and reproduction in any medium, provided you give appropriate credit to the original author(s) and the source, provide a link to the Creative Commons license, and indicate if changes were made. The Creative Commons Public Domain Dedication waiver (http://creativecommons.org/publicdomain/zero/1.0/) applies to the data made available in this article, unless otherwise stated.

\section{Radial-sided wrist injuries Scaphoid fracture}

Scaphoid fractures are the most commonly injured carpal bone [4] with a high incidence in college football players [5] and an increasing incidence in female athletes [6]. This hyperextension wrist injury tends to occur in a pronated, radially deviated hand. Presentation can range from disabling wrist pain to mild swelling and decreased range of motion. It is not uncommon to find a scaphoid nonunion with a remote history of a wrist sprain.

Located at the radial side of the carpus, athletes will complain of radial-sided wrist pain with exquisite tenderness in the anatomical snuff box, axial loading of the thumb, or pincer grasp. Radiographic assessment of the wrist should include a posteroanterior (PA), lateral, and ulnar deviated view. Unfortunately, due to subtle fracture lines and the irregular contour of the scaphoid, nondisplaced fractures can 
be missed on radiographs and advanced imaging with computed tomography (CT) scan for fracture identification or alignment. Additionally, magnetic resonance imaging (MRI) or bone scintigraphy for occult fracture may be needed to confirm the diagnosis $[7,8]$.

Treatment decisions depend upon fracture location and displacement, with strong surgical consideration being given to scaphoid fractures which are displaced and/or proximal. Whether treatment affects the athlete's continued participation in his or her sports within the context of the status of the season may also play a role in determining whether or not to operate. Due to retrograde blood supply, distal pole scaphoid fractures can effectively be treated nonsurgically. Proximal pole fractures are prone to avascular necrosis and necessitate stronger surgical consideration $[9,10]$. Likewise, displacement carries a relatively increased risk of nonunion and we would recommend surgical fixation. Operative management, mostly commonly in the form of headless compression screw fixation, often offers the fastest return to sports [11]. Cast immobilization may provide appropriate definitive treatment in a nondisplaced fracture or a temporizing measure for return to play. Return to athletic participation is based upon the athlete's handedness, his or her specific sports' requirements, and negotiating the bulk or restriction of the cast with respect to dexterity and/or strength [12] (Fig. 1).

\section{Scapholunate ligament tears}

Wrist instability commonly occurs in a spectrum of severity in hyperextension injuries. Contact sports such as football or rugby commonly place the athlete in a position of impact with hyperextension, ulnar deviation, and supination of the wrist that can lead to these injuries.

Because of the proximity of structures in the wrist, diagnosis of these injuries can be challenging. Pain in a loaded, extended wrist with tenderness in the dorsal wrist at the interval between the third and fourth extensor compartments suggests possible scapholunate (SL) interosseous ligament injury. Standard radiographic assessment with PA and lateral views may appear normal only showing increased flexion of the scaphoid (a signet ring sign on the PA view as in Fig. 2a). A PA clenched fist view may show greater than $5 \mathrm{~mm}$ of widening between the scaphoid and lunate (Terry Thomas sign) is diagnostic of a complete SL ligament tear [13]. Chronic tears may demonstrate a static SL gap on the PA film and an increased SL angle on the lateral consistent with dorsal intercalated segmental instability (DISI). Advanced imaging is commonly needed in the form of MRI with or without contrast arthrography [14].

Suspected tears or partial tears can respond to immobilization allowing the participant to still compete. Those with continued pain and dysfunction that interferes with their level of play will require wrist arthroscopy. Geissler et. al. [15] developed an arthroscopic grading system which helps guide management that ranges from immobilization for attenuation of an intact ligament to open reduction and repair for gross instability.

\section{Radial-sided tendinopathies}

Radial-sided wrist pain from overuse injuries requires careful evaluation. Accurate diagnosis using provocative maneuvers and identifying the precise location of maximal tenderness are paramount. Radiographic assessment can be indicated for ruling out fracture depending on the patient's history. Advanced imaging, such as MRI, is not routinely used.

The most common tendinopathy in the athlete is de Quervain's tenosynovitis [16]. Repetitive thumb extension and abduction can lead to a thickening of the abductor pollicis longus and extensor pollicis brevis tendons as they pass under the first extensor compartment retinaculum. Tenderness to palpation is approximately $2 \mathrm{~cm}$ proximal
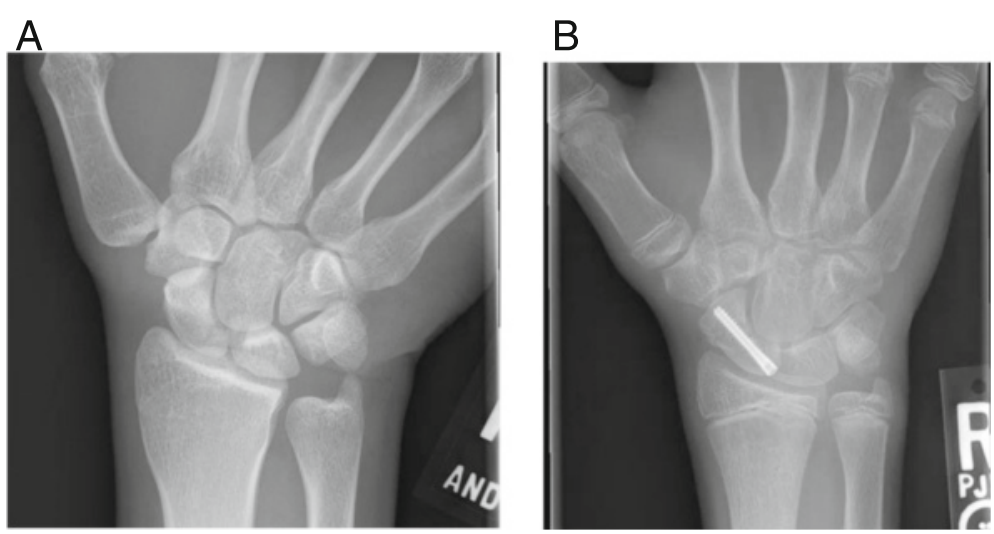

Fig. 1 a PA radiograph of a nondisplaced proximal pole scaphoid fracture in a recreational hockey player. $\mathbf{b}$ PA radiograph of a nondisplaced scaphoid waist fracture in a high school soccer player treated with headless compression screw fixation 

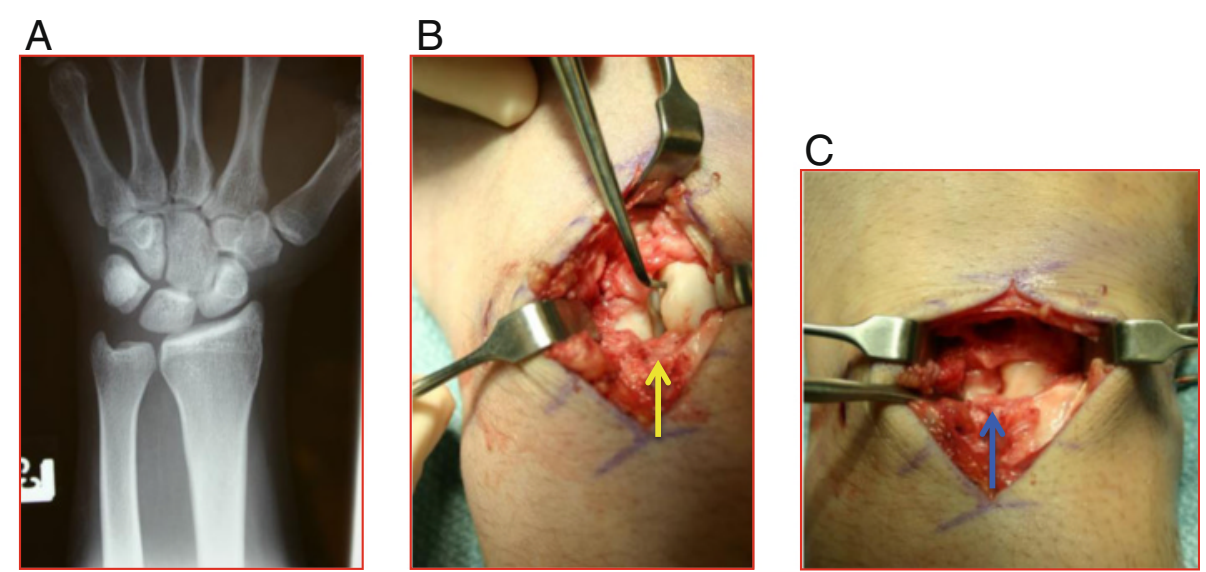

Fig. 2 a PA radiograph showing a flexed scaphoid (signet ring sign). b Intraoperative finding of a complete SL interosseous ligament tear with the tip of the probe on the scaphoid (yellow arrow). c Open reduction of the SL interval (blue arrow) prior to ligament repair

to the radial styloid and exacerbated by tucking the thumb under the other fingers while ulnarly deviating the wrist (a positive Finkelstein's sign) [17, 18].

Intersection syndrome, also called Oarsman's wrist, is caused by friction at the crossing of the tendons of the first extensor compartment as they pass over the tendons of the second extensor compartment (extensor carpi radialis longus and brevis) or a stenosing tenosynovitis within the second extensor compartment itself [19]. Pain is elicited with extension and radial deviation approximately $4-8 \mathrm{~cm}$ proximal to the radial styloid. Without careful attention to the location of pain, this can be misdiagnosed as de Quervain's tenosynovitis.

Tendonitis of the flexor carpi radialis is due to repetitive wrist flexion or acute overstretching of the wrist as can be seen in volleyball or water polo [20]. Pain develops from tendon thickening as it runs in its tunnel adjacent to the carpal tunnel. Pain typically courses from the radial palmar wrist crease towards the base of the second metacarpal made worse by resisted wrist flexion.

Conservative treatment for these tendinopathies begins by avoiding inciting events. Immobilization, stretching techniques, ice, and nonsteroidal anti-inflammatory medications can effectively diminish symptoms. Should symptoms persist, anesthetic/corticosteroid injections into the responsible tendon sheaths at the point of maximal tenderness can be of diagnostic and of therapeutic benefit. When recalcitrant to conservative measures, surgical release of the respective tunnel or compartment may be warranted.

\section{Ulnar-sided wrist injuries}

Extensor carpi ulnaris injury

Abnormalities of the extensor carpi ulnaris (ECU) covers an array of pathologies seen in golf, baseball, hockey, tennis players, and other racquet sports. Injury may present as acute or chronic encompassing tendinosis, subluxation, dislocation, or rupture causing pain with or without mechanical symptoms on the ulnar side of the wrist. The pathophysiology involves repetitive microtrauma or a sudden traumatic episode during wrist flexion, supination, and ulnar deviation such as the nondominant hand in a double-handed backhand in tennis or the leading hand in the downward phase of a golf stroke.

Injury to the ECU will typically present with pain over the ulnar aspect of the wrist. Tenderness to palpation in the ECU groove and pain with resisted extension and ulnar deviation are hallmarks of tendinopathy. Subluxation will give the sensation of snapping with supination and ulnar deviation of the wrist. The physician should also evaluate the triangular fibrocartilage complex (TFCC) as a peripheral tear can lead to ECU tendonitis. Radiographic assessment is not routinely required unless needed to rule out other causes of ulnar-sided wrist pain. Ultrasound (US) can be useful in identifying inflammatory changes or using a dynamic assessment to look for tendon subluxation or dislocation [21]. MRI can be helpful to assess other structures such as the TFCC.

Acute or chronic ECU tendinopathy can be managed with immobilization in wrist extension and ulnar deviation with progression to isometric and eccentric exercises. In cases of acute dislocation, reduction and immobilization with the forearm in pronation and the wrist in radial deviation for 4 months can be successful but not conducive to athletic participation [22]. Nonanatomic reconstruction of the subsheath with extensor retinaculum [23, 24] or, preferably, anatomic repair (Fig. 3) with reduction of the periosteum and subsheath back in the ulnar groove [25] are successful options to return to sports. 

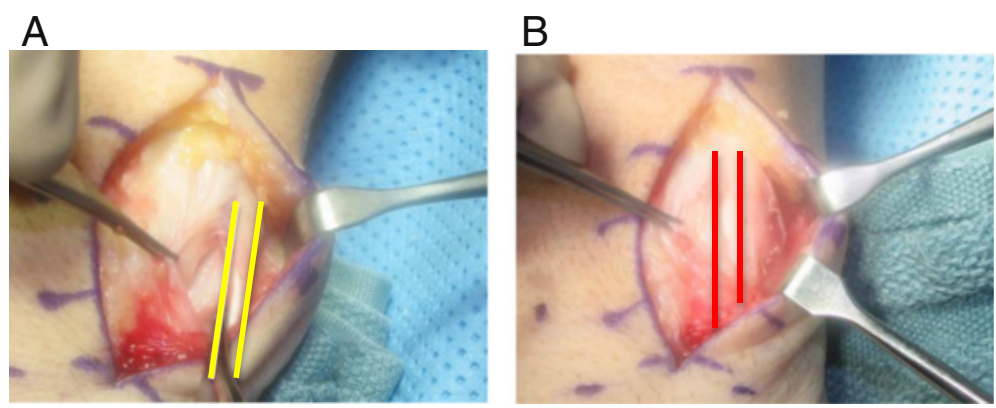

Fig. 3 a Intraoperative finding of a volarly subluxed ECU tendon (between yellow lines) in a recreational tennis player. $\mathbf{b}$ The ECU tendon back in its reduced position (red lines) after an anatomic repair of the subsheath

\section{Ulnar abutment}

The majority of load absorbed at the wrist is through the radiocarpal joint. In the ulnar neutral wrist, the distal ulna bears approximately $20 \%$ of forces. As the wrist becomes more ulnar positive, the ulnocarpal joint experiences increased forces leading to ulnar-sided wrist pain. Ulnar positivity can be a normal anatomic variant, the result of distal radius physeal arrest (so-called gymnast's wrist), or as a dynamic condition with grip and pronation $[26,27]$.

Rarely presenting after an acute injury, symptoms from ulnar abutment typically manifest as an insidious onset of pain with repetitive activities of pronation, gripping, ulnar deviation, axial loading, or combinations thereof which begin to affect the athlete's level of play. Tenderness to palpation at the prestyloid recess of the ulna and pain with wrist ulnar deviation as moved through a full arc of pronosupination (ulnocarpal stress test) [28] is characteristic of the exam. Standard PA radiograph may reveal ulnar positivity but when dynamic ulnar positivity is suspected, a pronated/maximum grip PA view may be helpful in making the diagnosis [27]. MRI is not always necessary but may be helpful in evaluating the TFCC, early chondral changes in the distal ulna and/or the ulnar lunate, or lunotriquetral interosseous ligament tears.

As a slowly progressive condition, acute surgical treatment is rarely warranted. Conservative measures to decrease symptoms and avoid provocative activities can allow continued participation. Immobilization between practices with or without nonsteroidal antiinflammatories can decrease pain. Corticosteroid injections as a diagnostic and therapeutic tool can be used in the more chronic setting [29]. If conservative measures fail to allow continued level of play or timing is optimal, surgical treatment can be used to halt the progression by decreasing ulnar positivity and debriding the degenerative TFCC tear. Arthroscopic debridement and ulnar shortening are the mainstays of treatment. While arthroscopic wafer resection enjoys the benefit of shorter recovery times [30-32], the gold standard is diaphyseal ulnar shortening osteotomy (Fig. 4) and has shown improvement in pain, motion, and function [33-35].

\section{Triangular fibrocartilage complex tears}

Another cause of ulnar-sided wrist pain, particularly in those athletes who grip and rotate baseball bats, racquets, or golf clubs, is injury to the TFCC. The TFCC is a soft tissue complex that supports the distal radioulnar joint. It also acts as an extension of the radial articular surface serving as a load-bearing structure of the carpus on the distal ulna $[3,36]$. In the acute setting, tears of the TFCC can occur with hyperextension and pronation of the axially loaded, ulnar deviated wrist. However, micro- or repetitive trauma can cause peripheral tears to the TFCC with rapid supination-pronation of the ulnar deviated wrist as seen with swinging a baseball bat.

Deep aching pain, pain with gripping, and occasionally mechanical symptoms of clicking with pronationsupination can be experienced. Tenderness at the prestyloid recess that is accentuated with extremes of rotation or translation of the ulna, anterior to posterior, is characteristic of the exam. Standard radiographic evaluation typically appears normal. MRI or MRA are commonly used to confirm the diagnosis (Fig. 5a) [37].

As repetitive trauma is more common in athletes, conservative treatment is typically employed if symptoms arise during season. Immobilization, with or without physical therapy if ECU irritation is involved, for a period of 3 months can be helpful at alleviating symptoms [38]. Recalcitrant or recurring symptoms require arthroscopy for definitive classification as set forth by Palmer [36]. Symptomatic peripheral TFCC tears should be repaired either open or with arthroscopic assistance (Fig. 5b, c) [39-43] and typically require 3 months before return to play. Symptomatic tears of the central articular disk which fail conservative management can be treated with arthroscopic debridement (with or without a concomitant ulnar shortening osteotomy if indicated), but are not amenable to repair. 

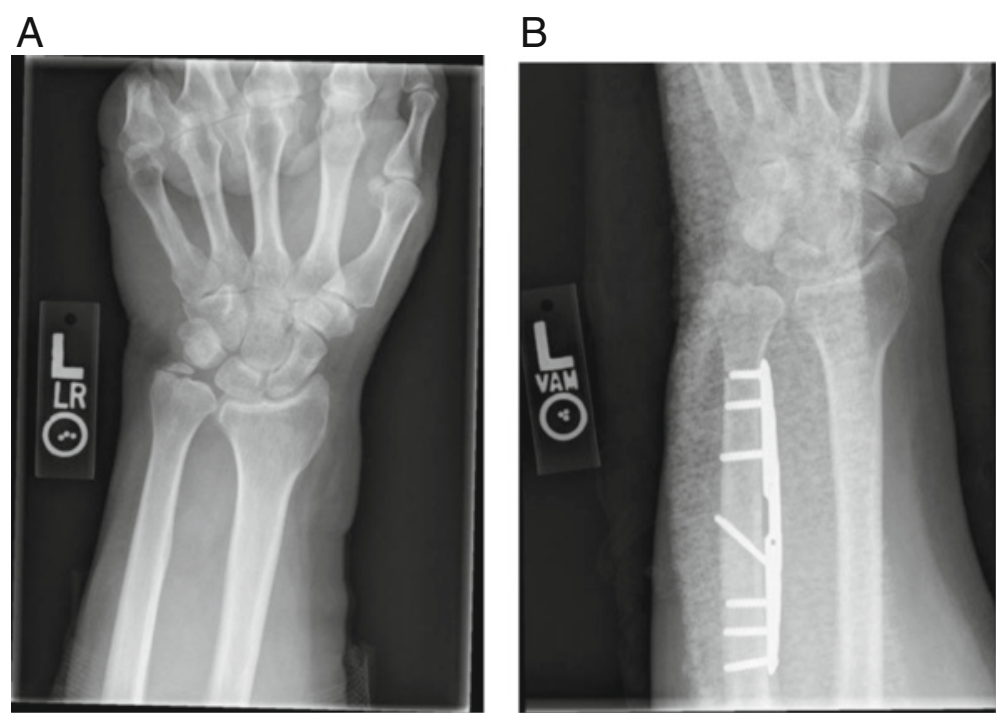

Fig. 4 a PA radiograph of a patient with ulnar abutment revealing both $6 \mathrm{~mm}$ of ulnar-positive variance and incidentally an ulnar styloid nonunion. $\mathbf{b}$ Neutral to $-1 \mathrm{~mm}$ of ulnar variance after a diaphyseal ulnar shortening osteotomy is performed
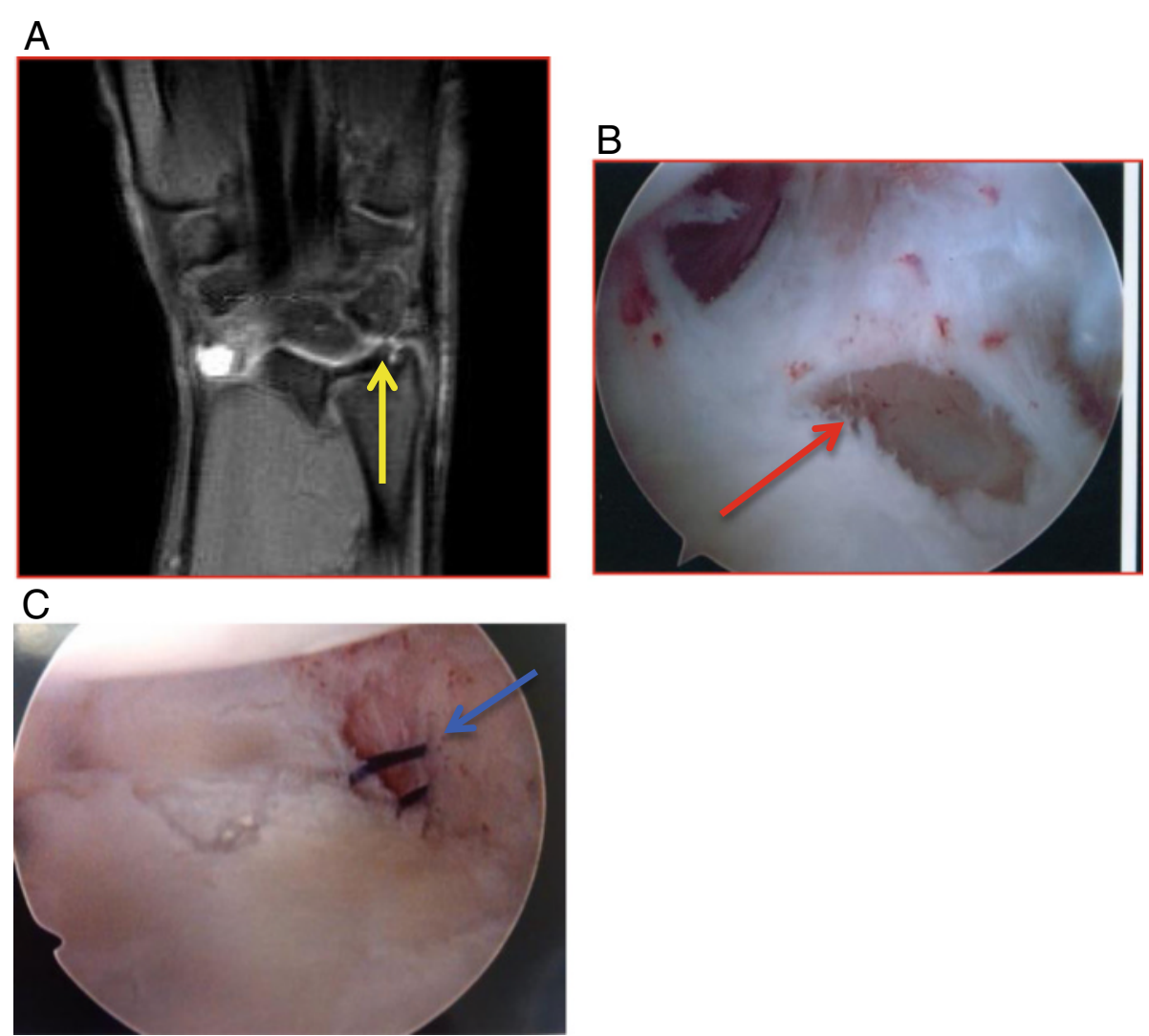

Fig. 5 a A T2-weighted coronal sequence of a wrist MRI revealing an ulnar-sided peripheral tear of the TFCC (yellow arrow). b Arthroscopy view from the three to four portal showing the peripheral tear (red arrow). c Intraoperative arthrosopic image during an arthroscopic-assisted outside-in repair using PDS suture (blue arrow) 


\section{Hook of the hamate fractures}

Direct blows from a golf club with the ground or from a baseball bat while "checking" a swing can result in hook of the hamate fractures. Infrequently, repeated lesser impacts from the same can result in stress fractures.

Hypothenar pain is present with palpation or with forceful grip. A pull test is performed by flexing the ring and small finger in the ulnar deviated wrist which produces pain by the deforming force of the flexors. Because the hook makes up one border of Guyon's canal, dysesthesias in the ulnar nerve distribution or weak grip may be present. A carpal tunnel radiograph, in addition to standard PA and lateral views, is needed to make an accurate diagnosis. If radiographs are negative, a CT scan can be most helpful in defining the bony injury (Fig. 6).

Most fractures on presentation are subacute or chronic making definitive treatment with immobilization difficult. Whalen et. al. [44] reported healing of all six fractures they treated with immobilization, but other reports have showed less success and may risk flexor digitorum profundus (FDP) tendon injury $[45,46]$. Biomechanical studies have suggested a possible decrease in flexion force with hook of the hamate excision lending consideration for open reduction and internal fixation [47, 48]. Nonetheless, excision of the hook of the hamate fragment is currently the standard of care and has produced successful results with return to play in 6 weeks [49-53].

\section{Hand/finger injuries}

\section{Thumb ulnar collateral ligament tears}

Ulnar collateral ligament (UCL) injuries of the thumb are extremely common $[54,55]$ and often seen in skiing,

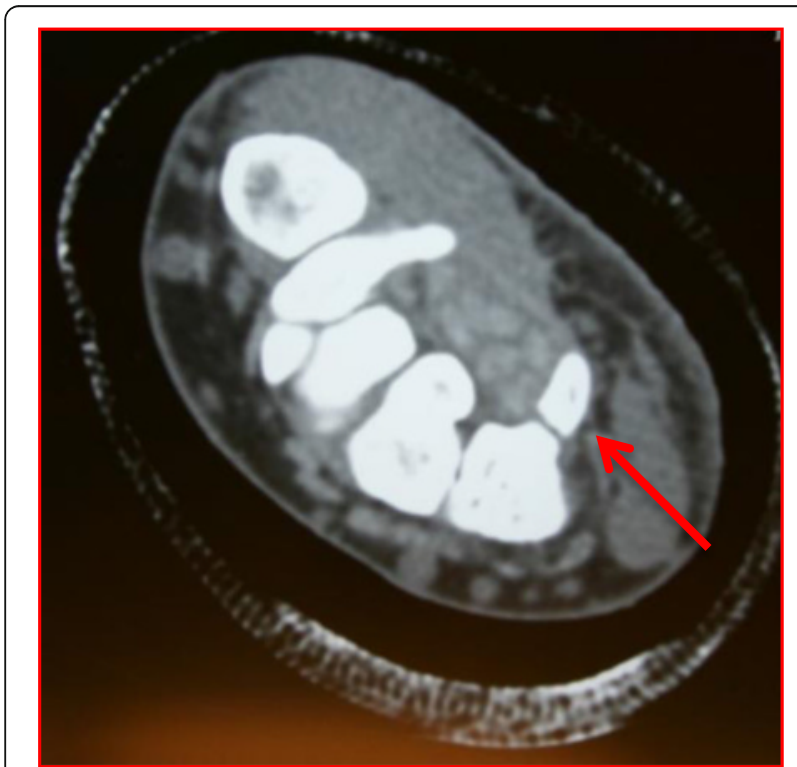

Fig. 6 Axial CT image demonstrating a hook of the hamate fracture (red arrow) in a college hockey player basketball, and football. Injury occurs from an abduction moment at the thumb metacarpophalangeal joint (MCPJ) such as a fall onto an outstretched hand with the thumb abducted. An acute thumb UCL injury has been dubbed a skier's thumb [56], in contrast to chronic attritional insufficiency of the ligament which is referred to as a gamekeeper's thumb [57].

Acute injuries often present with pain, ecchymosis, and swelling on the ulnar aspect of the thumb MCPJ. Stress examination with the thumb in extension and $30^{\circ}$ of flexion is the most important aspect of the physical exam [58]. Laxity of $30^{\circ}$ total, greater than $15^{\circ}$ to the contralateral, or lack of endpoint (Fig. 7a) are all strongly suggestive of ligament injury $[59,60]$. The thumb UCL has two portions, the proper (more dorsally located) and the accessory (more volar) ligaments. Laxity at $30^{\circ}$ of MCPJ flexion and at full MCPJ extension is suggestive of injury to both the proper and the accessory components, respectively. Radiographic assessment is important for excluding bony fragments but US or MRI (Fig. 7b) is often used to confirm the diagnosis. A Stener lesion refers to interposition of the adductor aponeurosis in between the torn off UCL and its proximal phalanx insertion, making healing impossible.

Immobilization with a hand-based thumb spica splint or a cast with the interphalangeal (IP) joint free is appropriate for treating UCL partial tears with a firm endpoint to valgus stress testing at the MCPJ. For complete tears without an endpoint, surgery is recommended. Most UCL injuries are amenable to direct repair using either transosseous sutures or a suture anchor, although more chronic tears may require reconstruction with a variety techniques available [61-63]. Both UCL repair and reconstruction have shown satisfactory results with decreased pain and increased function [64].

\section{Metacarpal/phalangeal fractures}

Accounting for $10 \%$ of all fractures presenting to the emergency department, metacarpal and phalangeal fractures are common injuries [65-67]. Injuries occur from falls, direct blows, or crush during sporting activity, although stress fractures have rarely been noted in racquet sports $[68,69]$. Incidence is highest in contact sports such as football, lacrosse, and hockey [2, 70-72].

While swelling, ecchymosis, and deformity can be present, not all fractures lead to obvious deformity. For those with obvious deformity, a reduction maneuver should not be attempted without radiographic or fluoroscopic examination first in order to ensure appropriate treatment of the specific fracture, dislocation, or fracture dislocation [73]. In less obvious injuries, careful clinical examination of the hand with respect to digital range of motion (ROM), the finger cascade, and comparison of any subtle malrotation to the contralateral hand might 


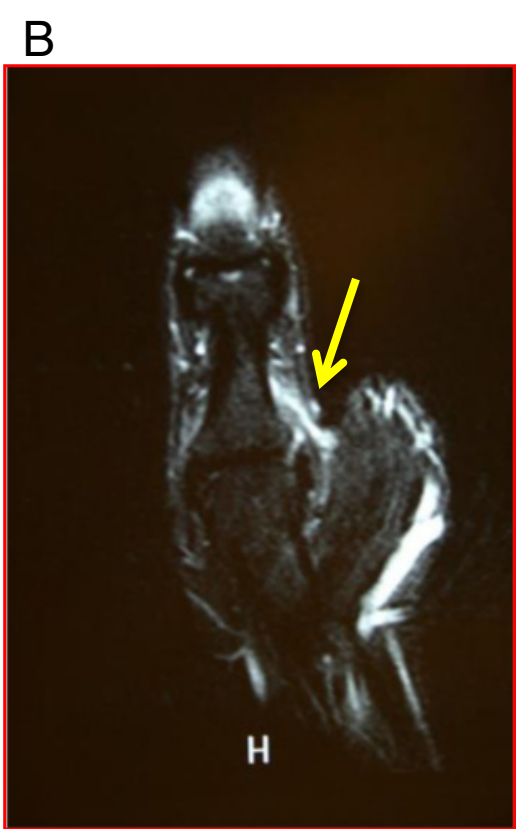

Fig. 7 a Preoperative photograph demonstrating a patient with no endpoint to valgus stress testing of the thumb MCP joint. $\mathbf{b}$ A T2-weighted coronal sequence demonstrating a complete tear of the UCL which is detached from the proximal phalanx (yellow arrow)

point to an occult injury. Radiographic assessment with anteroposterior (AP), oblique, and lateral views are standard. Training rooms have been increasingly outfitted with mini-fluoroscopy units for rapid evaluation, although their sensitivity in detecting fractures of the smaller bones with possible intra-articular involvement has been questioned [74]. If further imaging for fracture characteristics is needed, a CT scan may be indicated.

Many fractures can be treated nonoperatively if acceptable alignment can be maintained with immobilization. When conservative treatment is inadequate, operative fixation is indicated. In the athlete, operative fixation may be sought to allow faster return to play.

\section{Metacarpal fractures}

Metacarpal base fractures occur from an axial load with the wrist in flexion. Eponyms such as Bennett and reverse-Bennett fractures are used to describe the characteristic fractures of the thumb and small finger metacarpal. Bennett fractures are sometimes associated with significant displacement as strong muscular forces tend to pull the base of shaft in abduction and proximally. As an intra-articular fracture, acceptable alignment to decrease the chance of symptomatic, posttraumatic arthritis is desirable [75]. If there is more than $25 \%$ articular involvement or more than $1 \mathrm{~mm}$ of articular step-off or gapping between fracture fragments, operative fixation is usually indicated. Closed or open reduction of the fracture stabilized with Kirschner wires (K-wires) or screws is frequently needed.
Metacarpal shaft fractures are typically stable due to the intermetacarpal ligaments, although the net flexion moment at the distal segment pulls these fractures into a classic apex dorsal position. Acceptable angulation depends on the metacarpal involved with no greater than $10^{\circ}$ tolerated in the index and up to $30^{\circ}$ in the small finger [76]. Shortening of greater than $2 \mathrm{~mm}$ is generally not well tolerated as it leads to an extensor lag that can eventually not be compensated for by the hyperextensible MCPJ [77]. Careful clinical exam should assess not only for the finger cascade but also for the rotational deformity. Mild rotation in the metacarpal can lead to significant finger overlap [76]. Immobilization of isolated fractures in acceptable alignment is usually possible but the type of sports and position can limit tolerability. Multiple forms of fixation are possible each with its own relative advantages and disadvantages. Kwire fixation offers a soft tissue friendly form of fixation, adequate in maintaining alignment but protruding pins risk infection and pin migration/breakage and preclude further participation with exposed hardware in gripping athletics (i.e., tennis, basketball, golf). Lag screw fixation (Fig. 8a, b), indicated in long oblique fractures, offers minimal dissection and an anatomic reduction, but stability may not allow an expedited return to play. Plate and screw fixation (Fig. 8c, d) offers the stability of a relatively quicker return to play [78], but may expose the player to an increased risk of infection, tendon irritation, extensor adhesions, and the need for future hardware removal. Which treatment is selected should be a collaboration between the surgeon, the athlete, and the training staff. 
A

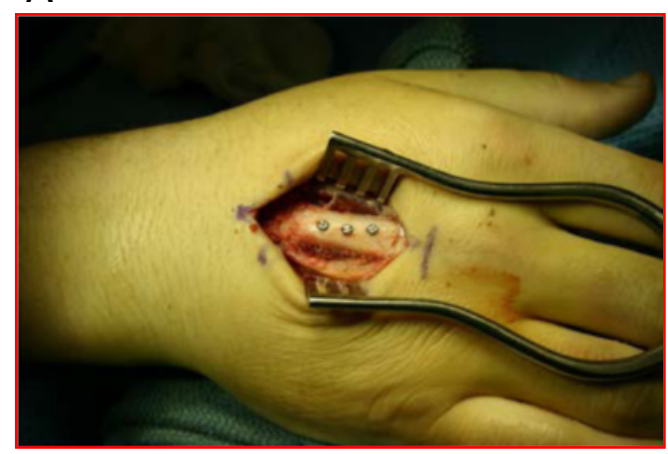

C

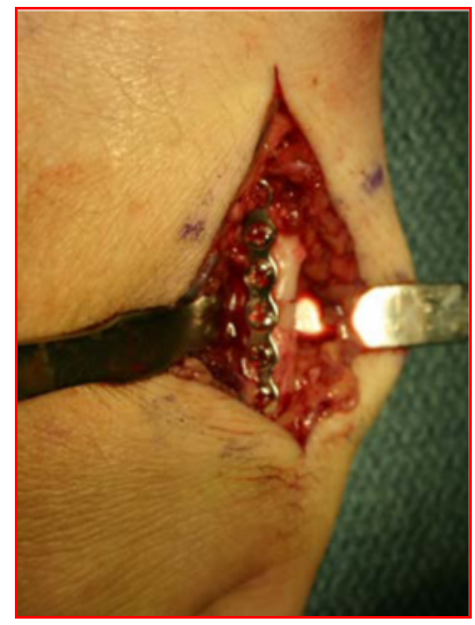

D

Fig. 8 a Intraoperative and $\mathbf{b}$ fluoroscopic images of a long oblique metacarpal shaft fracture secured with three lag screws. $\mathbf{c}$ Intraoperative and d fluoroscopic images of a transverse shaft fracture secured with a plate and screws

Metacarpal neck fractures are the most common metacarpal fracture as they occur at the metadiaphyseal junction at the area of the weakest bone. The socalled Boxer's fracture is an eponym referring to metacarpal neck fractures of the small finger which result from an impact punching with a closed fist. Immobilization is typically adequate. Various forms of immobilization with the hand in intrinsic plus position or buddy taping with a short arm cast do not show any functional difference in outcome [79]. Acceptable alignment follows the same principles as for metacarpal shaft fractures with apex dorsal angulation being the most obvious deformity and increasing in toleration as the injury moves from the index to the small finger, with approximately $40^{\circ}-50^{\circ}$ of apex dorsal angulation well tolerated in the small finger. When acceptable alignment cannot be achieved or immobilization cannot be tolerated for the athlete, operative fixation is occasionally considered. Both Kwire and plate (Fig. 9) fixation have produced reasonably good outcomes, each with its own inherent risk/ benefit profile as previously discussed.
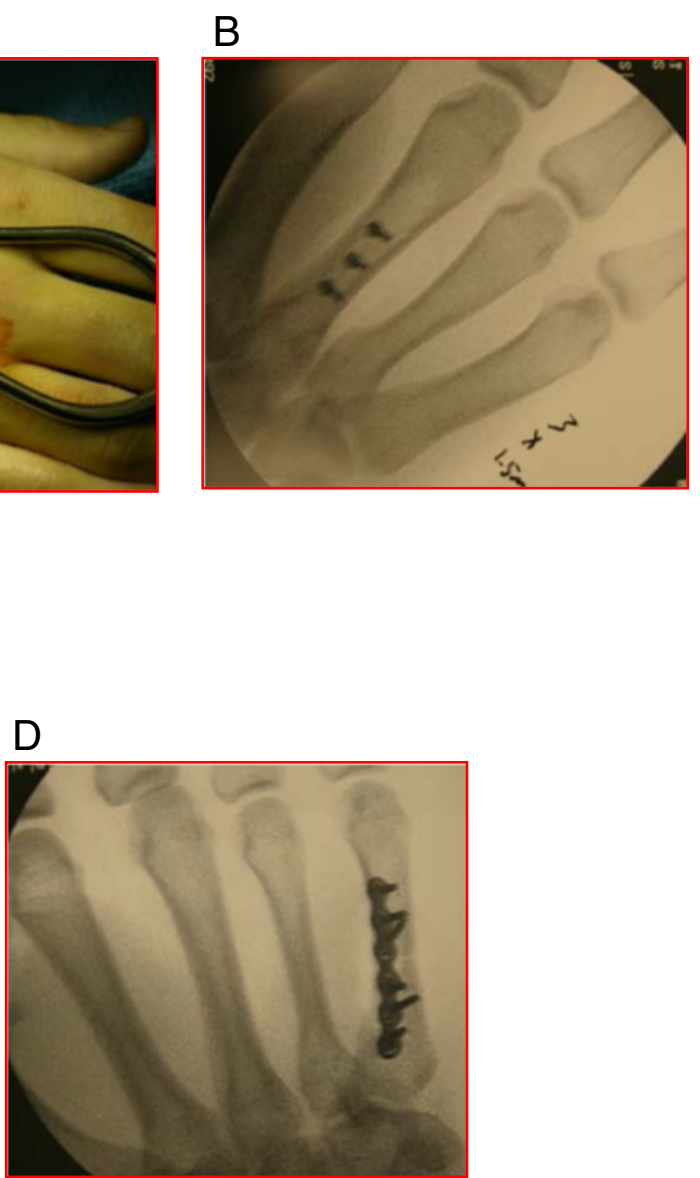

\section{Phalangeal fractures}

Shaft fractures of the proximal and middle phalanges can occur in a variety of patterns, but buddy taping and/ or protective splint wear in acceptable alignment can allow fast return to play. Extra-articular fractures without rotational malalignment, less than $15^{\circ}$ of angulation, and less than $6 \mathrm{~mm}$ of shortening are indicated for conservative treatment [80]. Operative fixation with open versus closed reduction using either K-wires (Fig. 10), screws, or plate and screws as fixation is sometimes required, especially when there is digital malrotation [81]. The athlete's demands, the status of the season, and the fracture's characteristics combine to dictate the optimal form of treatment.

When fractures enter the articular surface of the phalangeal base or condyle, operative fixation should be sought unless less than $1 \mathrm{~mm}$ of gap or step-off is present. Fractures can range from simple articular fractures, fixed with K-wires or screws, to comminuted pilon-type fractures which may require a distraction fixator in order to restore articular alignment through ligamentotaxis [82-84]. 


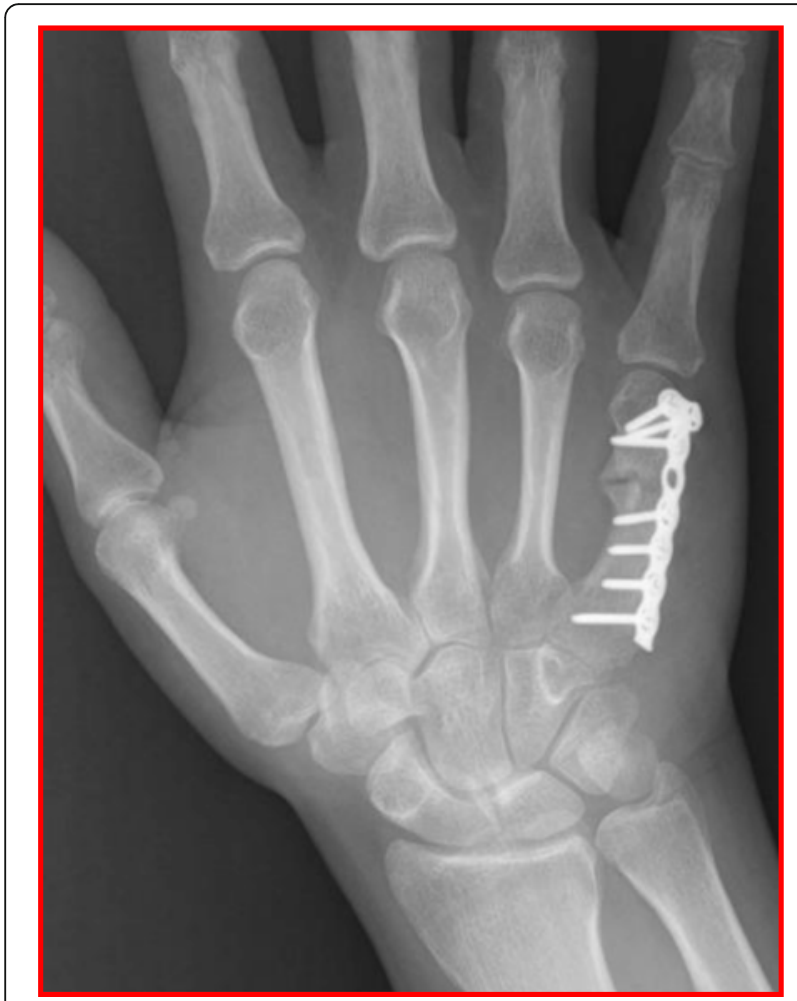

Fig. 9 Plate and screw fixation of an angulated fifth metacarpal neck fracture in a high school running back

Distal phalanx fractures, due to crush mechanisms, are typically stable with surrounding soft tissue and the overlying nail plate. The vast majority of these are treated nonoperatively; however, careful attention should be paid to those distal phalanx fractures with associated nail bed trauma, such as displaced physeal (Seymour type) fractures in children.

Dislocations or fracture dislocations, particularly those that spontaneously reduce on the field, can often be overlooked in athletics. These comprise a spectrum of hyperextension jamming-type injuries from pure dorsal proximal interphalangeal (PIP) joint dislocations, to dorsal dislocations with volar plate avulsion fractures, to fracture dislocations involving a significant portion of the middle phalangeal articular surface. Radiographic assessment should be performed after every apparent dislocation to assess the percentage of articular surface involvement. In the setting of an acute PIP dislocation, with or without a volar plate avulsion fleck of bone, the PIP joint is most likely stable and early flexion ROM rehabilitation with buddy taping is appropriate. Fracture dislocations of the PIP joint which involve more than $30 \%$ of the middle phalangeal articular surface may be unstable and should be treated much more cautiously, often requiring surgery. Those PIP fractures which involve more than $50 \%$ of the PIP

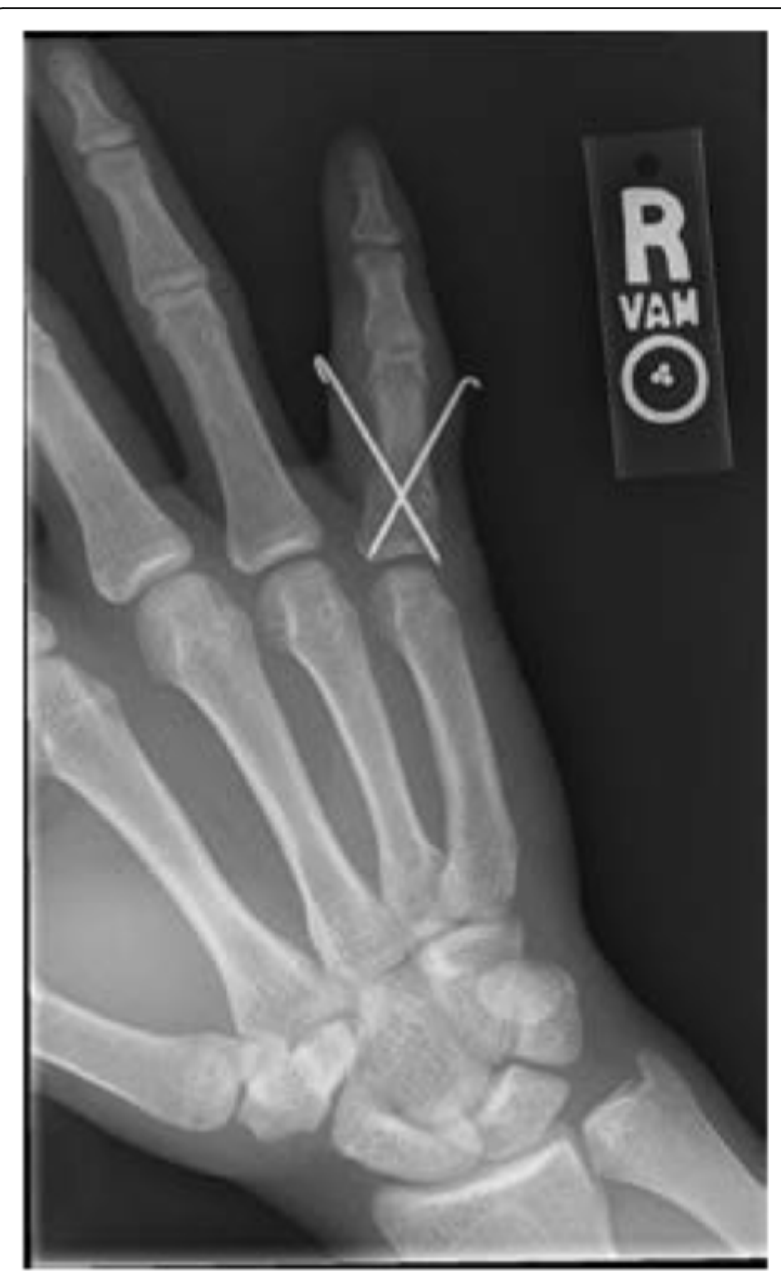

Fig. 10 A PA radiograph of a small finger transverse proximal phalanx fracture with clinical malrotation which was treated with closed reduction and crossed K-wires

joint surface (Fig. 11) are clearly unstable and require surgical management.

\section{Sagittal band rupture}

A Boxer's knuckle refers to an injury of the sagittal band, which is the structure that normally keeps the extensor

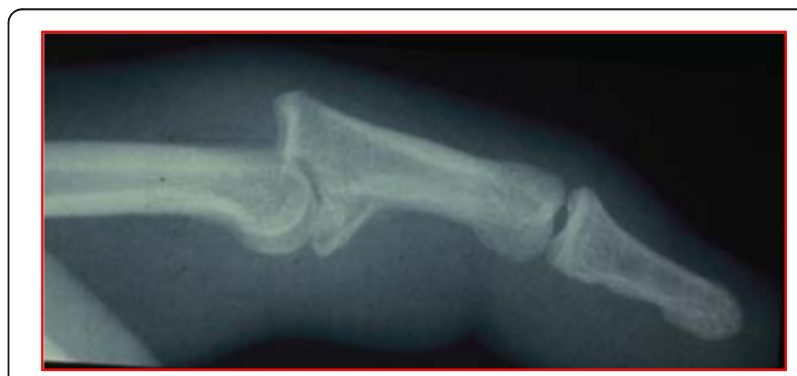

Fig. 11 Lateral radiograph of a dorsal fracture dislocation of the PIP joint with $50 \%$ articular involvement of the middle phalanx 
digitorum communis (EDC) tendon centralized over the metacarpal head at the level of the MCP joint [85]. The sagittal bands are composed of transverse, sagittal, and oblique fibers that can be injured by blunt trauma over the MCPJ with a clenched fist impact [86, 87]. Painful EDC tendon subluxation can ensue causing an inability to achieve active extension of the finger at the MCP joint (cannot obtain, but can maintain extension).

Athletes can present with an acute or chronic injury. The central rays are more often affected due to more prominent bony structure, thinner superficial tissue, longer radial fibers, and single extensor tendons $[86,88]$. Weakness of MCPJ extension in the affected digit, painful tendon subluxation usually in an ulnar direction, and tenderness over the injured sagittal band are evident on exam.

Sagittal band injury without subluxation or dislocation can be treated with MCPJ extension splinting with the PIP joint free. When there is frank EDC subluxation or dislocation, a trial of conservative treatment can still be attempted, although results in the literature have been mixed [89-91] which have lead most surgeons to treat these injuries operatively (Fig. 12b, c) [87, 92]. MCPJ immobilization after repair or reconstruction is required to allow adequate healing after which aggressive ROM can be initiated. Athletes should be cautioned about returning to sports too quickly to prevent wound complications and recurrence $[91,92]$.

\section{Central slip ruptures}

Volar dislocation or forced flexion at the PIP joint can lead to acute rupture or chronic attenuation of the triangular ligament at the distal end of the central slip.
These injuries are seen more commonly in basketball and volleyball players [93]. Injury leads to the lateral bands migrating volarly with resultant PIP joint flexion and hyperextension at the distal interphalangeal (DIP) joint known as a boutonniere deformity. As chronicity sets in, progressive loss of motion is seen at the PIP and DIP joints.

Evaluation with history and physical examination should elicit any history of volar PIP joint dislocation and try to isolate pain to the central slip insertion. Assessing DIP flexibility with the PIP joint resisted in extension (Elson's test) is a helpful method for assessing the central slip [94]. An intact central slip would have a flexible DIP while an incompetent central slip would have a rigid DIP. Radiographs should be obtained with or without a history of dislocation to assess for bony avulsion of the central slip and PIP joint alignment.

Splinting of the affected digit with the PIP joint in extension and PIP free is appropriate in order to allow the central slip tendon to heal in as closed to an anatomic position as possible. Leaving the DIP joint free for flexion assists in pulling the lateral bands into normal alignment and decreases stiffness [95]. Athletes close to season completion can be allowed to continue competition as long as their participation is not hindered by the splint [96]. Rarely do acute injuries require operative treatment unless a displaced bony fragment is identified and requires screw fixation versus excision with repair [97] after which early rehabilitation can begin [97, 98].

Chronic central slip injuries with a fixed Boutonniere deformity create a challenging situation for the treating surgeon. Treatment begins by attempting to obtain a passively correctable deformity by using an extension splint,
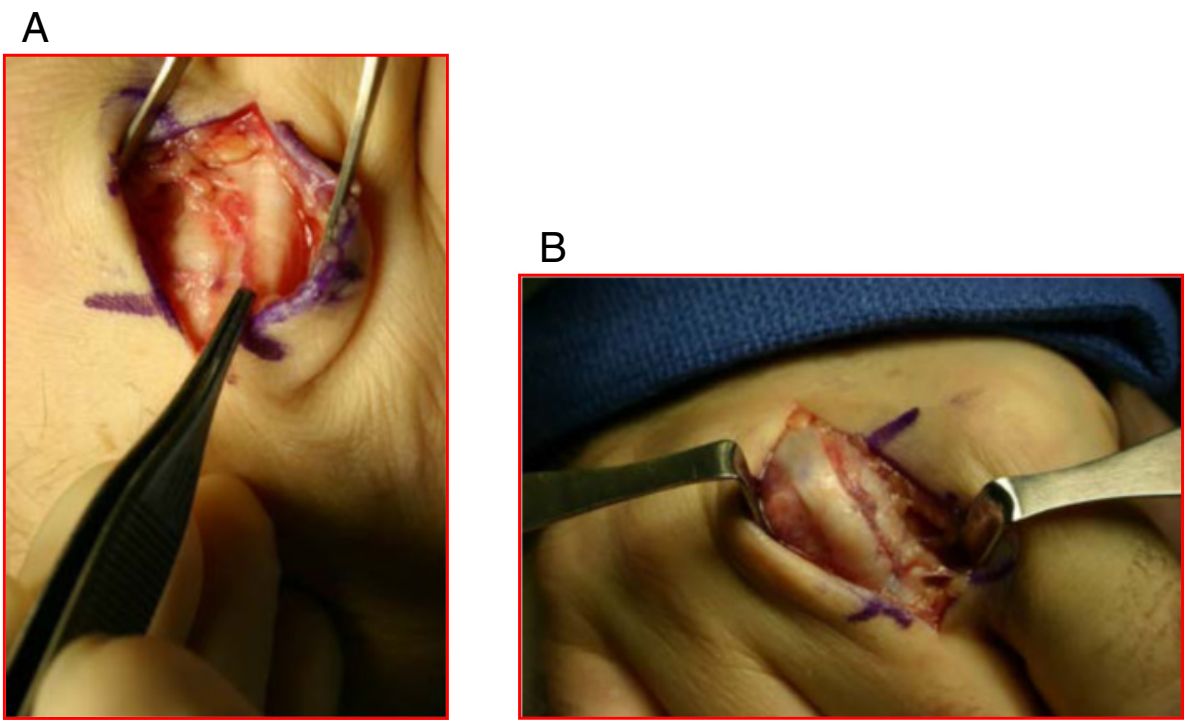

Fig. 12 a Intraoperative findings of a patient with a torn radial sagittal band and ulnarly subluxed EDC tendon before repair $\mathbf{b}$ and after repair 
serial casting, or a dynamic external fixator [99-101] to stretch the contracted volar structures. Once a supple deformity is achieved, reconstruction can be attempted with a variety of techniques such as extensor tenolysis and transverse retinacular ligament mobilization or release, terminal extensor tenotomy with lateral band lengthening, and central slip reconstruction [102-104]. Because treatment of a chronic deformity results in much worse outcomes [97, 105, 106], athletes should be strongly encouraged to seek treatment in the acute period.

\section{Pulley ruptures}

Closed annular pulley ruptures occur most commonly in rock climbers due to the high demand placed on the flexor tendon system in the hanging and crimping positions $[107,108]$. Pulley ruptures typically involve the A2 or A4 pulleys and occur most often in the middle and ring fingers. Previous work has evaluated the force required to produce an A2 pulley tear and loads experienced during these vulnerable maneuvers finding they are at particular risk for climbers [109-112].

Athletes present with the acute onset of pain over the volar aspect of the affected digit which may exhibit swelling and ecchymosis. They can usually isolate the event to a particular movement or slip leading to a forceful digital contraction and feeling a pop. Tenderness to palpation can usually be localized over the affected pulley but diffuse swelling of the entire flexor tendon sheath may cause pain with passive extension. While rupture of the A2 and A4 pulley are generally required to show significant bowstringing, relative bowstringing may be appreciated or a flexion lag may be evident on exam. Applying external pressure over the affected area and asking the patient to flex the digit may reduce his or her pain further supporting the diagnosis. While pulley ruptures are not evident on plain radiographs, MRI or US may be helpful in confirming the diagnosis [113-116].

Isolated pulley ruptures can be effectively treated nonoperatively with taping or pulley rings that externally provide support for the flexor tendon. However, in the case of multiple pulley ruptures, or failed nonoperative treatment, reconstruction is indicated [117]. A variety of graft sources such as palmaris longus tendon, extensor retinaculum, or an excised flexor digitorum superficialis (FDS) slip are available. Early ROM to facilitate tendon gliding is encouraged with higher loading not allowed until 6 months postoperatively.

\section{Jersey finger}

Forceful hyperextension of the DIP joint leading to FDP avulsion, as seen with a jersey tearing away from a finger, is most commonly seen in football and rugby players. Eccentric loading of the FDP has shown the ring finger to be most susceptible to injury due to its position in power grip, decreased independent motion, and failure strength compared to other digits [118-122].

The athlete may or may not recall the moment of injury to the digit. Swelling is commonly present which may cause the athlete to not seek attention assuming that the lack of DIP flexion is simply a fingertip sprain. Commonly, they present with complaints of decreased motion or stiffness and lack of strength. Continuity of the flexor system can be assessed passively by tenodesis effect or by holding the MCPJ and PIP joints extended and asking the athlete to flex the DIP in isolation. In cases of a bony avulsion (Fig. 13) in which the trapped fragment cannot migrate proximally through the A4 or A5 pulley, some flexion may actually be possible but decreased and painful. Radiographic assessment can be helpful at identifying a bony avulsion with amount of retraction. For pure tendon failures, MRI can provide information about continuity and retraction of the tendon $[123,124]$, but is not usually necessary.

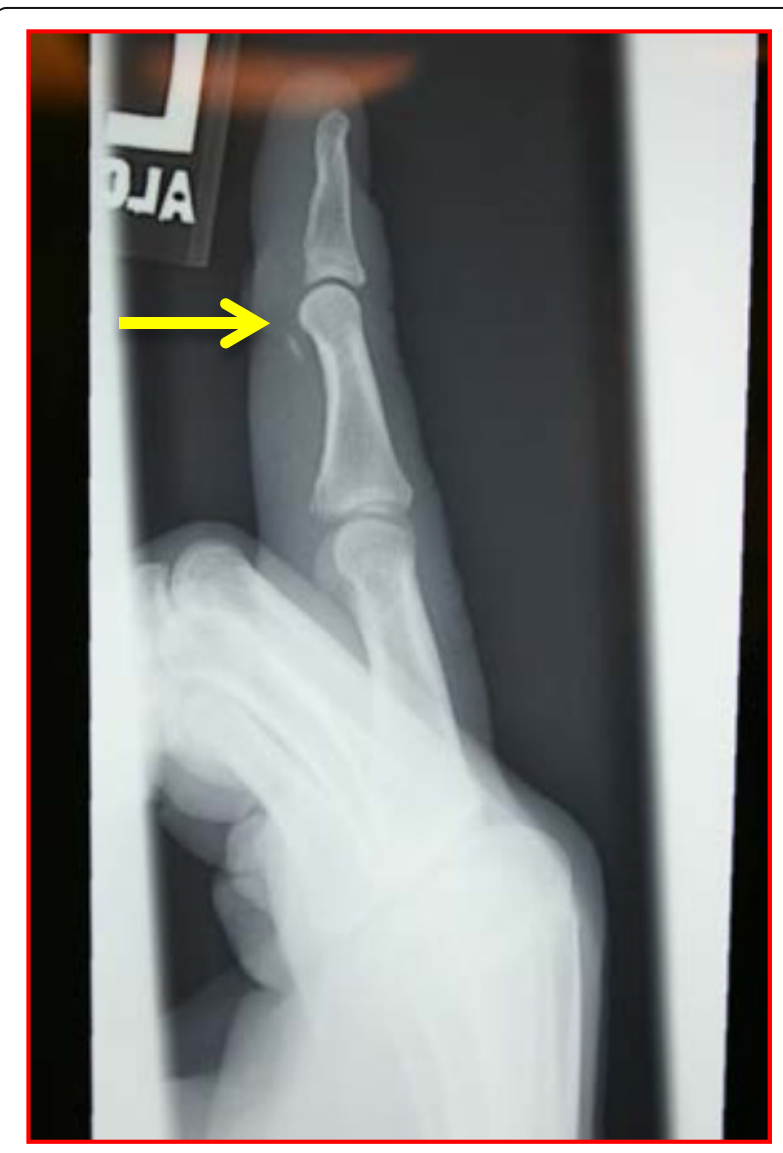

Fig. 13 Lateral radiograph of a ring finger of a patient whose finger got caught on a basketball net showing an FDP bony avulsion fracture with the fragment caught up distal to the A4 pulley level (yellow arrow) 
Further migration or retraction of the tendon can compromise the nutritional supply to the flexor tendon. Therefore, operative intervention is warranted as soon as possible. Various methods for repair have been described, but they all involve advancement of the intact, viable tendon to the base of the distal phalanx, often using transosseous sutures tied over a dorsal button or suture anchors [125-129]. Chronic injuries may require primary or staged flexor tendon reconstruction with a tendon graft, or in the case of an intact FDS, a DIP joint arthrodesis could be considered [121].

\section{Mallet finger}

Mallet finger injuries refer to the disruption of the terminal extensor tendon from the distal phalanx, with or without an avulsed bony fragment. Its occurrence most commonly in baseball has lead to the eponym "baseball finger" [130], but is also seen in football, basketball, and rugby [131]. Its mechanism of injury involves forceful flexion of an extended DIP joint.

The hallmark of physical exam for mallet fingers is a fingertip that is "drooped" in flexion with the inability to extend at the DIP joint. Dorsal DIP swelling and ecchymosis are commonly seen but in cases without bony involvement are often surprisingly painless [132]. Evaluation should include assessment for swan neck deformity (flexed DIP with extended PIP) as this may cause more functional deficit than a DIP flexion deformity. Radiographic assessment is necessary to assess for a bony mallet avulsion fragment (Fig. 14) and alignment of the DIP joint.

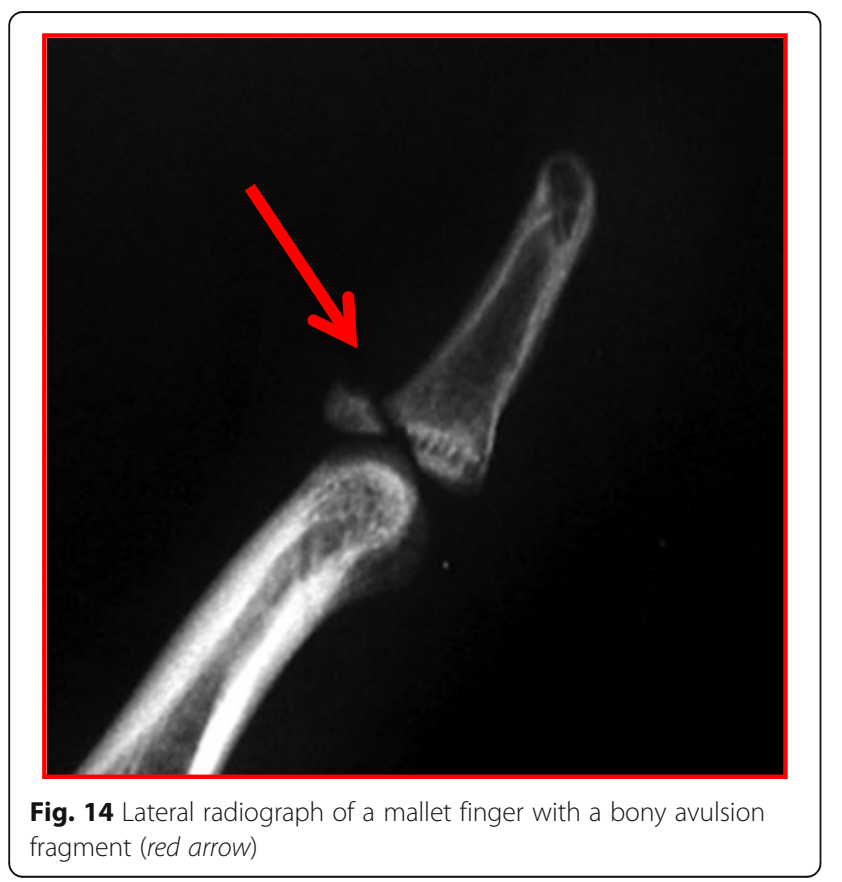

Conservative treatment with extension splinting of the DIP joint is appropriate for almost all mallet fingers, including those with bony fragments as long as there is no significant joint subluxation [133-135]. Full-time DIP splinting with the PIP joint free is recommended for 6 weeks around the clock oftentimes with an additional 6 weeks of nighttime splinting [136-141]. For athletes experiencing splint complications such as dorsal skin maceration or difficulty with the compliance of full-time splinting, buried K-wire immobilization of the DIP joint offers an alternative treatment path with possible return to sports albeit with relatively high inherent risks [142].

\section{Conclusions}

Hand and wrist injuries in athletics are common and can have a significant impact in multiple areas. Knowledge of these entities and special consideration for the athlete can help the team physician effectively treat these players and help them achieve their goals.

\section{Acknowledgements \\ No additional acknowledgements.}

Funding

No funding sources were utilized in the preparation of this review.

Availability of data and materials

All specified information and data was retrieved from original and review articles readily available through PubMed.com.

\section{Authors' contributions}

DMA formulated the outline, searched and retrieved the articles, and drafted the manuscript. CMR and CME assisted in the outline and drafting/revision of the manuscript. All authors read and approved the final manuscript.

\section{Authors' information}

DMA is a current Orthopaedic Sports Medicine fellow that will be matriculating into Hand and Microvascular fellowship following its completion. CMR is an assistant professor of Orthopaedic Surgery and Hand surgeon with certificate of added qualification in hand surgery. CME is an assistant professor of Orthopaedic Surgery and Orthopaedic Sports Medicine physician and team doctor with certificate of added qualification in Sports Medicine.

Competing interests

The authors declare that they have no competing interests.

Consent for publication

Gross, radiographic, and magnetic resonance imaging are nonidentifiable.

Ethics approval and consent to participate

Not applicable.

Received: 27 May 2016 Accepted: 28 August 2016

Published online: 16 September 2016

\section{References}

1. Rettig AC. Athletic injuries of the wrist and hand. Part 1. Traumatic injuries of the wrist. Am J Sports Med. 2003;31:1038-48.

2. Amadio PC. Epidemiology of hand and wrist injuries in sports. Hand Clin. 1990:6:379-81.

3. Geissler WB, Burkett JL. Ligamentous sports injuries of the hand and wrist. Sports Med Arthrosc Rev. 2014;22(1):39-44.

4. Sendher R, Ladd AL. The scaphoid. Orthop Clin North Am. 2013;44(1):107-20.

5. Geissler WB. Arthroscopic management of scaphoid fractures in athletes. Hand Clin. 2009;25(3):359-69. 
6. Fowler JR, Hughes TB. Scaphoid fractures. Clin Sports Med. 2015;34:37-50.

7. Garcia RM, Ruch DS. Management of scaphoid fractures in the athlete: open and percutaneous fixation. Sports Med Arthrosc. 2014;22(1):22-8.

8. Mallee WH, Wang J, Poolman RW, et al. Computed tomography versus magnetic resonance imaging versus bone scintigraphy for clinically suspected scaphoid fractures in patients with negative plain radiographs. Cochrane Database Syst Rev. 2015;5(6):CD010023.

9. Cooney III WP, Dobyns JH, Linscheid RL. Nonunion of the scaphoid: analysis of the results from bone grafting. J Hand Surg Am. 1980;5(4):343-54.

10. Buijze GA, Ochtman L, Ring D. Management of scaphoid nonunion. J Hand Surg Am. 2012;37(5):1095-100.

11. Belsky MR, Leibman MI, Ruchelsman DE. Scaphoid fracture in elite athlete. Hand Clin. 2012;28(3):269-78.

12. Rettig AC, Kollias SC. Internal fixation of acute stable scaphoid fractures in the athlete. Am J Sports Med. 1996;24(2):182-6.

13. Elsaftawy A. Radial wrist extensors as a dynamic stabilizers of scapholunate complex. Pol Przegl Chir. 2013;85(8):452-9.

14. Shahabpour M, Staelens $B$, Van Overstraeten L, et al. Advanced imaging of the scapholunate ligamentous complex. Skeletal Radiol. 2015;44(12):1709-25.

15. Geissler WB, Freeland AE, Savoie FH, et al. Intracarpal soft tissue lesios associated with an intra-articular fracture of the distal end of the radius. J Bone Joint Surg Am. 1996;78:357-65.

16. Rumball JS, Lebrun CM, Di Ciacca SR, Orlando K. Rowing injuries. Sports Med. 2005;35(6):537-55.

17. Elliot BG. Finkelstein's test: a descriptive error that can produce a false positive. J Hand Surg. 1992;17B:481-2.

18. Posner MA. Differential diagnosis of wrist pain: tendinitis, ganglia, and other syndromes. In: Peimer CA, editor. Surgery of the hand and upper extremity. New York: McGraw-Hill; 1996. p. 838-41.

19. Hanlon DP, Luellen JR. Intersection syndrome: a case report and review of literature. J Emerg Med. 1999;17(6):969-71.

20. Brink PR, Franssen BB, Disseldorp DJ. A simple blind tenolysis for flexor carpi radialis tendinopathy. Hand (NY). 2015;10(2):323-7.

21. Campbell D, Campbell R, O'Connor P, Hawkes R. Sports-related extensor carpi ulnaris pathology: a review of functional anatomy, sports injury, and management. Br J Sports Med. 2013;47:1105-11.

22. Patterson SM, Picconatto WJ, Alexander JA, et al. Conservative treatment of an acute traumatic extensor carpi ulnaris tendon subluxation in a collegiate basketball player: a case report. J Athl Train. 2011;46:574-6.

23. Burkhart SS, Wood MB, Linscheid RL. Posttraumatic recurrent subluxation of the extensor carpi ulnaris tendon. J Hand Surg Am. 1982;7:1-3.

24. Eckhardt WA, Palmer AK. Recurrent dislocation of extensor carpi ulnaris tendon. J Hand Surg AM. 1981;6:629-31.

25. MacLennan AJ, Nemechek NM, Waitayawinyu T, et al. Diagnosis and anatomic reconstruction of extensor carpi ulnaris subluxation. J Hand Surg Am. 2008;33:59-64.

26. Friedman SL, Palmar AK, Short WH, et al. The change in ulnar variance with grip. J Hand Surg Am. 1993;18(4):713-6.

27. Tomaino MM. The importance of pronated grip x-ray view in evaluating ulnar variance. J Hand Surg Am. 2000;25(2):352-7.

28. Nakamura R, Horii E, Imaeda T, et al. The ulnocarpal stress test in the diagnosis of ulnar-sided wrist pain. J Hand Surg Br. 1997;22(6):719-23.

29. Jarrett CD, Baratz ME. The management of ulnoarpal abutment and degenerative triangular fibrocartilage complex tears in the competitive athlete. Hand Clin. 2012;28(3):329-37.

30. Minami A, Ishikawa J, Suenaga $\mathrm{N}$, et al. Clinical results of treatment of triangular fibrocartilage complex tears by arthroscopic debridement. J Hand Surg Am. 1996;21(3):406-11.

31. Tomaino MM, Weiser RW. Combined arthroscopic TFCC debridement and wafer resection of the distal ulna in wrists with triangular fibrocartilage complex tears and positive ulnar variance. J Hand Surg Am. 2001;26(6):1047-52.

32. Nagle DJ. Triangular fibrocartilage complex tears in the athlete. Clin Sports Med. 2001;20(1):155-66.

33. Iwasaki $\mathrm{N}$, Ishikawa J, Kato $\mathrm{H}$, et al. Factors affecting results of ulnar shortening impaction syndrome. Clin Orthop Relat Res. 2007;465:215-9.

34. Bark GH, Lee HJ, Gong HS, et al. Long term outcomes of ulnar shortening osteotomy for idiopathic ulnar impaction syndrome: at least 5-years of follow up. Clin Orthop Surg. 2011;3(4):295-301.

35. Moermans A, Degreef I, DeSmet L. Ulnar shortening osteotomy for the ulnar idiopathic impaction syndrome. Scand J Plast Reconstr Surg Hand. 2007:41(6):310-4.
36. Palmer AK. Triangular fibrocartilage complex lesions: a classification. J Hand Surg Am. 1989;4:594-606.

37. Pahwa S, Srivastava DN, Sharma R, Gamanagatti S, Kotwal PP, Sharma V. Comparison of conventional MRI and MR arthrography in the evaluation wrist ligament tears: a preliminary experience. Indian J Radiol Imaging. 2014;24(3):259-67.

38. Geissler WB, Short WH. Repair of peripheral radial TFCC tears. In: Geissler WB, editor. Wrist Arthroscopy. New York: Springer; 2005. p. 42-9.

39. Trumble TE, Gilbert $M$, Vedder N. Isolated tears of the triangular fibrocartilage: management by early arthroscopic repair. J Hand Surg Am. 1997;22:57-65.

40. DeAraujo W, Poehling G, Kuzma G. New Tuohy needle technique for triangular fibrocartilage complex repair: preliminary studies. Arthroscopy. 1996;12:699-703.

41. Corso S, Savoie F, Geissler W, et al. Arthroscopic repair of peripheral avulsions of the triangular fibrocartilage complex of the wrist: a multicenter study. Arthroscopy. 1997;13:78-84.

42. Estrella EP, Hung LK, Ho PC, et al. Arthroscopic repair of triangular fibrocartilage complex tears. Arthroscopy. 2007;23:729-37.

43. Geissler WB. Arthroscopic management of peripheral ulnar tears of the triangular fibrocartilage complex. In: Slutsky DJ, editor. Principles and Practice of Wrist Surgery. Philadelphia: Saunders Elsevier; 2010. p. 205-12.

44. Whalen JL, Bishop AT, Linscheid RL. Nonoperative treatment of acute hamate hook fractures. J Hand Surg Am. 1992;17(3):507-11.

45. Carroll RE, Lakin JF. Fracture of the hook of the hamate: acute treatment. Trauma. 1993;34(6):803-5.

46. Stark HH, Chao EK, Zemel NP, et al. Fracture of the hook of the hamate. J Bone Joint Surg Am. 1989;71(8):1202-7.

47. Watson HK, Rogers WD. Nonunion of the hook of the hamate: an argument for bone grafting the nonunion. J Hand Surg Am. 1989;14(3):486-90.

48. Demirkan F, Calandruccio JH, DiAngelo D. Biomechanical evaluation of flexor tendon function after hamate hook excision. J Hand Surg Am. 2003; 28(1):138-43.

49. Stark HH, Jobe FW, Boyes $\mathrm{JH}$, et al. Fracture of the hook of the hamate in athletes. J Bone Joint Surg Am. 1977;59(5):575-82.

50. Devers BN, Douglas KC, Naik RD, et al. Outcomes of hook of hamate fracture excision in high-level amateur athletes. J Hand Surg Am. 2013:38(1):72-6.

51. Futami T, Aoki H, Tsukamoto Y. Fracture of the hook of the hamate in athletes. 8 cases followed for 6 years. Acta Orthop Scand. 1993;64(4):469-71.

52. Aldridge III JM, Mallon WJ. Hook of the hamate fractures in competitive golfers: results of treatment by excision of the hook of the hamate. Orthopedics. 2003;26(7):717-19.

53. Parker RD, Berkowitz MS, Brahms MA, et al. Hook of the hamate fractures in athletes. Am J Sports Med. 1986;14(6):517-23.

54. Rhee PC, Jones DB, Kakar S. Management of thumb metacarpophalangeal ulnar collateral ligament injuries. J Bone Joint Surg Am. 2012;94(21):2005-12.

55. Baskies MA, Lee SK. Evalaution and treatment of injuries of the ulnar collateral ligament of the thumb metacarpophalangeal joint. Bull NYU Hosp Jt Dis. 2009;67(1):68-74.

56. Gerber C, Senn F, Matter P. Skier's thumb. Surgical treatment of rcent injuries to the ulnar collateral ligament of the thumb's metacarpophalangeal joint. A J Sports Med. 1981:9(3):171-7.

57. Campbell CS. Gamekeeper's thumb. J Bone Joint Surg Br. 1955;37-B(1):148-9.

58. Tang P. Collateral ligament injuries of the thumb metacarpophalangeal joint. J Am Acad Orthop Surg. 2011;19(5):287-96.

59. Morgan WJ, Slowman LS. Acute hand and wrist injuries in athletes: evaluation and management. J Am Acad Orthop Surg. 2001;9(6):389-400.

60. Osterman AL, Hayken GD, Bora Jr FW. A quantitative evaluation of thumb function after ulnar collateral repair and reconstruction. J Trauma. 1981; 21(10):854-61.

61. Badia A, Prakash K. Arthroscopic and open primary repair of acute thumb metacarpophalangeal joint radial and ulnar collateral ligament disruptions. In: Wiesel SW, editor. Operative techniques in orthopaedic surgery. Philadelphia,: Lippincott Williams \& Wilkins; 2010. p. 2342-8.

62. Glickel SZ, et al. Ligament replacement for chronic instability of the ulnar collateral ligament of the metacarpophalangeal joint of the thumb. J hand Surg Am. 1993;18(5):930-41.

63. Oka Y, Harayama H, Ikeda M. Reconstructive procedure to repair chronic injuries to the collateral ligament of metacarpophalangeal joints of the hand. Hand Surg. 2003;8(1):81-5. 
64. Samora JB, et al. Outcomes after injury to the thumb ulnar collateral ligament-a systematic review. Clin J Sport Med. 2013;23(4):247-54.

65. Centers for Disease Control and Prevention. Sports-related injuries among high school athletes: United States, 2005-06 school year. MMWR Morb Mortal Wkly Rep. 2006;55(38):1037-40.

66. Bernstein ML, Chung KC. Hand fractures and their management: an international view. Injury. 2006;37(11):1043-8.

67. Immerman I, Livermore MS, Szabo RM. Use of emergency department services for hand, wrist, and forearm fractures in the United States in 2008. J Surg Orthop Adv. 2014;23(2):98-104.

68. Hickey GJ, Fricker PA, McDonald WA. Injuries of young elite female basketball players over a six-year period. Clin J Sport Med. 1997;7:252-6.

69. Waninger KN, Lombardo J. Stress fracture of index metacarpal in an adolescent tennis player. Clin J Sport Med. 1995;5:63-6.

70. Nakashian MN, Pointer $L$, Owens BD, et al. Incidence of metacarpal fractures in the US population. Hand (NY). 2012;7(4):426-30.

71. Rettig AC, Ryan R, Shelbourne KD, et al. Metacarpal fractures in the athlete Am J Sports Med. 1989;17(4):567-72.

72. Swenson DM, Yard EE, Collins CL, et al. Epidemiology of US high schoo sports-related fractures. 2005-2009. Clin J Sport Med. 2010;20(4):293-9.

73. Cotterell $\mathrm{H}$, Richard MJ. Metacarpal and phalangeal fractures in athletes. Clin J Sports Med. 2015;34:69-98.

74. Capo JT, Kinchelow T, Orillaza NS, et al. Accuracy of fluoroscopy in closed reduction and percutaneous fixation of simulated Bennett's fracture. J Hand Surg Am. 2009;34:637-41.

75. Bushnell BD, Draeger RW, Crosby CG, et al. Management of intra-articular metacarpal base fractures of the second through fifth metacarpals. J Hand Surg Am. 2008;33(4):573-83.

76. Royle SG. Rotational deformity following metacarpal fracture. J Hand Surg Br. 1990;15(1):124-5.

77. Strauch RJ, Rosenwasser MP, Lunt JG. Metacarpal shaft fractures: the effect of shortening on the extensor tendon mechanism. J Hand Surg Am. 1998; 23:519-23.

78. Etier BE, Scillia AJ, Tessier DD, et al. Return to play following metacarpal fractures in football players. Hand. 2015;10:762-66.

79. Hofmeister EP, Kim J, Shin AY. Comparison of two methods of immobilization of fifth metacarpal neck fractures: a prospective randomized study. J hand Surg Am. 2008;33(8):1362-8.

80. Gaston RG, Chadderdon C. Phalangeal fractures: displaced/nondisplaced. Hand Clin. 2012;28(3):395-401.

81. Shim WC, Yang JW, Roh SY, et al. Percutaneous cerclage wiring technique for phalangeal fractures. Tech Hand Up Extrem Surg. 2014;18(1):36-40.

82. Finsen V. Suzuki's pins and rubber traction for fractures of the base of the middle phalanx. J Plast Surg Hand Surg. 2010;44(4-5):209-13.

83. Figl $M$, Weninger $P$, Hofbauer $M$, et al. Results of dynamic treatment of fractures of the proximal phalanx of the hand. J Trauma. 2011;70(4):852-6.

84. Nilsson JA, Rosberg HE. Treatment of proximal interphalangeal joint fractures by the pins and rubbers traction system: a follow-up. J Plast Surg Hand Surg. 2014;48(4):259-64.

85. Gladden JR. Boxer's knuckle: a preliminary report. Am J Surg. 1957;93(3):388-97.

86. Rayan GM, Murray D, Chung KW, Rohrer M. Classification and treatment of closed sagittal band injuries. J Hand Surg Am. 1994;19(4):509-4.

87. Melone Jr CP, Polatsch DB, Beldner S. Disabling hand injuries in boxing: boxer's knuckle and traumatic carpal boss. Clin Sports Med. 2009;28(4):609-21.

88. Rayan GM, Murray D, Chung KW, Rohrer M. The extensor retinacular system at the metacarpophalangeal joint. Anatomical and histological study. J Hand Surg. 1997;22B:585-90.

89. Catalano III LW. Closed treatment of nonrheumatoid extensor tendon dislocations at the metacarpophalangeal joint. J Hand Surg Am. 2006;31(2):242-5.

90. Araki S, Ohtani T, Tanaka T. Acute dislocation of the extensor digitorum communis tendon at the metacarpophalangeal joint. A report of five cases. J Bone Joint Surg Am. 1987;69(4):616-9.

91. Nagaoka M. Extensor retinaculum graft for chronic boxer's knuckle. J Hand Surg Am. 2006;31(6):947-51.

92. Hame SL, Melone CP. Boxer's knuckle in the professional athlete. Am J Sports Med. 2000;28(6):879-82.

93. Weiland AJ. Boutonniere and pulley rupture in elite baseball players. Hand Clin. 2012;28(3):447.

94. Rubin J, Bozentka DJ, Bora FW. Diagnosis of closed central slip injuries: a cadaveric analysis of non-invasive tests. J Hand Surg Br. 1996;21(5):614-6.
95. Peterson JJ, Bancroft LW. Injuries of the fingers and thumb in the athlete. Clin Sports Med. 2006;25(3):527-42.

96. Lourie GM. Boutonniere and pulley rupture football commentary. Hand Clin. 2012;28(3):451-2.

97. Elfar J, Mann T. Fracture-dislocations of the proximal interphalangeal joint. J Am Acad Orthop Surg. 2013;21(2):88-98.

98. Tekkis PP. The role of mini-fragment screw fixation in volar dislocations of the proximal interphalangeal joint. Arch Orthop Trauma Surg. 2001;121(1-2):121-2.

99. Smith DW. Boutonniere and pulley rupture in elite basketball. Hand Clin. 2012;28(3):449-50.

100. El-Sallakh S. Surgical management of chronic boutonniere deformity. Hand Surg. 2012;17(3):359-64.

101. Williams K, Terrono AL. Treatment of boutonniere finger deformity in rheumatoid arthritis. J Hand Surg Am. 2011;36(8):1388-93.

102. Marino JT, Lourie GM. Boutonniere and pulley rupture in elite athletes. Hand Clin. 2012;28(3):437-45.

103. Curtis RM, Reid RL, Provost JM. A staged technique for the repair of the traumatic boutonniere deformity. J Hand Surg Am. 1983;8(2):167-71.

104. To P, Watson JT. Boutonniere deformity. J Hand Surg Am. 2011;36(1):139-42.

105. Rosenstadt BE, Glickel SZ, Lane LB, et al. Palmar fracture dislocation of the proximal interphalangeal joint. J Hand Surg Am. 1998;23:811-20.

106. Grundberg AB. Anatomic repair of boutonniere deformity. Clin Orthop Relat Res. 1980;153:226-9.

107. Schoffl VR, Schoffl I. Injuries to finger flexor pulley system in rock climbers: current concepts. J Hand Surg Am. 2006;31:647-54.

108. Schweizer A. Biomechanical properties of the crimp grip position in rock climbers. J Biomech. 2001;34:217-23.

109. Lin GT, Amadio PC, An KN, et al. Biomechanical analysis of finger flexor pulley reconstruction. J Hand Surg Br. 1989;14:278-82.

110. Burtscher M, Jenny E. Common injuries with sports mountain climbers. Prakt Sport Trauma Sportmed. 1987;2:15-21.

111. Bollen SR. Injury to the A2 pulley in rock climbers. J Hand Surg Br. 1990;15: 268-70.

112. Roloff I, Schoffl V, Vigouroux L, et al. Biomechanical model for the determination of the forces acting on the finger pulley system. J Biomech. 2006;39:915-23.

113. Bodner G, Rudisch A, Gabl M, et al. Diagnosis of digital flexor tendon annular pulley disruption: comparison of high frequency ultrasound and MRI. Ultraschall Med. 1999;20:131-36.

114. Hauger $\mathrm{O}$, Chung CB, Lektrakul N, et al. Pulley system in the fingers: normal anatomy and simulated lesions in cadavers at MR imaging, $C T$, and US with and without contrast material distention of the tendon sheath. Radiology. 2000;217:201-12.

115. Martinoli C, Bianchi S, Cotton A. Imaging of rock climbing injuries. Semin Musculoskeletal Radiol. 2005;9:334-45.

116. Guntern D, Goncalves-Matoso V, Gray A, et al. Finger A2 pulley lesions in rock climbers: detection and characterization with magnetic resonance imaging at 3 Tesla-initial results. Invest Radiol. 2007:42:435-41.

117. Seiler III JG, Leversedge FJ. Digital flexor sheath: repair and reconstruction of the annular pulleys and membranous sheath. J South Orthop Assoc. 2000;9:81-90.

118. Bynum Jr DK, Gilbert JA. Avulsion of flexor digitorum profundus: anatomic and biomechanical considerations. J Hand Surg Am. 1988;13:222-27.

119. Leddy JP, Packer JW. Avulsion of the profundus tendon insertion in athletes. J Hand Surg Am. 1977;2:66-9.

120. Lunn PG, Lamb DW. "Rugby finger"-avulsion of profundus of ring finger. J Hand Surg Br. 1984;9:69-71.

121. Leddy JP. Avulsions of the flexor digitorum profundus. Hand Clin. 1985:1:77-83

122. Manske PR, Lesker PA. Avulsion of the ring finger flexor digitorum profundus tendon: an experimental study. Hand. 1978;10:52-5.

123. Kumar BA, Tolat AR, Threepuraneni $G$, et al. The role of magnetic resonance imaging in late presentation of isolated injuries of the flexor digitorum profundus tendon in the finger. J Hand Surg Br. 2000;25:95-7.

124. Clavero JA, Alomar X, Monill JM, et al. Imaging of ligament and tendon injuries of the fingers. Radiographics. 2002;22:237-56.

125. Dovan $\pi$, Ritty $T$, Ditsios $K$, et al. Flexor digitorum profundus tendon to bone tunnel repair: a vascularization and histologic study in canines. J Hand Surg Am. 2005:30:246-57.

126. Dovan TT, Gelberman RH, Kusano N, et al. Zone I flexor digitorum profundus repair: an ex-vivo biomechanical analysis of tendon to bone repair in cadavers. J hand Surg Am. 2005;30:258-66. 
127. McCallister WV, Ambrose HC, Katolik LI, et al. Comparison of pullout button versus suture anchor for zone I flexor tendon repair. J Hand Surg Am. 2006;31:246-51.

128. Matsuzaki H, Zaegel MA, Gelberman RH, et al. Effect of suture material and bone quality on the mechanical properties of zone I flexor tendon-bone reattachment with bone anchors. J Hand Surg Am. 2008;33:709-17.

129. Chu JY, Chen T, Awad HA, et al. Comparison of an all-inside suture technique with traditional pull-out suture and suture anchor repair techniques for flexor digitorum profundus attachment to bone. J Hand Surg Am. 2013;38:1084-90.

130. Gaston RG, Loeffler BJ. Sports-specific injuries of the hand and wrist. Clin Sports Med. 2015;34:1-10.

131. Chauhan A, Jacobs B, Andoga A, Baratz ME. Extensor tendon injuries in athletes. Sports Med Arthrosc Rev. 2014;22(1):45-55.

132. McMurtry JT, Isaacs J. Extensor tendon injuries. Clin Sports Med. 2015;34:167-80.

133. Garberman SF, Diao E, Peimer CA. Mallet finger: results of early versus delayed closed treatment. J Hand Surg Am. 1994;19(5):850-2.

134. Warren RA, Kay NR, Ferguson DG. Mallet finger: comparison between operative and conservative management in those cases failing to be cured by splintage. J Hand Surg Br. 1988;13(2):159-60.

135. Stack HG. A modified splint for mallet finger. J Hand Surg Br. 1986;11(2):263.

136. Richards SD. A model for the conservative management of mallet finger. J Hand Surg Br. 2004;29(1):61-3.

137. Pike J. Blinded, prospective, randomized clinical trial comparing volar, dorsal, and custom thermoplastic splinting in treatment of acute mallet fnger. J Hand Surg Am. 2010;35(4):580-8.

138. Bendre AA, Hartigan BJ, Kalainov DM. Mallet finger. J Am Acad Orthop Surg. 2005;13(5):336-44.

139. Brzezienski MA, Schneider LH. Extensor tendon injuries at the distal interphalangeal joint. Hand Clin. 1995;11(3):373-86.

140. Simpson D, McQueen MM, Kumar P. Mallet deformity in sport. J Hand Surg Br. 2001;26(1):32-3.

141. Hovgaard C, Klareskov B. Alternative conservative treatment of mallet finger injuries by elastic double finger bandage. J Hand Surg Br. 1988;13(2):154-5.

142. Nakamura K, Nanjyo B. Reassessment of surgery for mallet finger. Plast Reconstr Surg. 1994;93(1):141-9.

\section{Submit your next manuscript to BioMed Central and we will help you at every step:}

- We accept pre-submission inquiries

- Our selector tool helps you to find the most relevant journal

- We provide round the clock customer support

- Convenient online submission

- Thorough peer review

- Inclusion in PubMed and all major indexing services

- Maximum visibility for your research

Submit your manuscript at www.biomedcentral.com/submit
Biomed Central 